\title{
DYNAMIC THREE-DIMENSIONAL IMAGING OF THE MITRAL VALVE AND LEFT VENTRICLE BY RAPID SONOMICROMETRY ARRAY LOCALIZATION
}

Joseph H. Gorman III, MD

Krishanu B. Gupta, PhD

James T. Streicher, $\mathrm{PhD}$

Robert C. Gorman, MD

Benjamin M. Jackson, MS

Mark B. Ratcliffe, MD

Daniel K. Bogen, MD, PhD

L. Henry Edmunds, Jr., MD
Objectives. The first objective was to develop a quantitative method for tracking the three-dimensional geometry of the mitral valve. The second was to determine the complex interrelationships of various components of the mitral valve in vivo. Methods and results. Sixteen sonomicrometry transducers were placed around the mitral valve anulus, at the tips and bases of both papillary muscles, at the ventricular apex, across the ventricular epicardial short axis, and on the anterior chest wall before and during cardiopulmonary bypass in eight anesthetized sheep. Animals were studied later on 17. occasions. Reproducibility of derived chord lengths and three-dimensional coordinates from sonomicrometry array localization, longevity of transducer signals, and the dynamics of the mitral valve and left ventricle were studied. Reproducibility of distance measurements averages 1.6\%; Procrustes analysis of three-dimensional arrays of coordinate locations predicts an average error of $2.2 \mathrm{~mm}$. Duration of serial sonomicrometry array localization signals ranges between 60 and 151 days (mean 114 days). Sonomicrometry array localization demonstrates the saddle-shaped mitral anulus, its minimal orifice area immediately before end-diastole, and uneven, apical descent during systole. Papillary muscles shorten only 3.0 to $3.5 \mathrm{~mm}$. Sonomicrometry array localization demonstrates nonuniform torsion of papillary muscle transducers around a longitudinal axis and shows rotation of papillary muscular bases toward each other during systole. Conclusion. Tagging of ventricular structures in experimental animals by sonomicrometry array localization images is highly reproducible and suitable for serial observations. In sheep the method provides unique, quantitative information regarding the interrelationship of mitral valvular and left ventricular structures throughout the cardiac cycle. (J Thorac Cardiovasc Surg 1996;112:712-26)
$S^{\text {o }}$ onomicrometry array localization (SAL) identiSfies an array of individual piezoelectric, sonomicrometry transducers affixed to the heart in threedimensional space. ${ }^{1}$ In SAL the three-dimensional

From the Department of Surgery, School of Medicine, and Department of Bioengineering, School of Enginecring and Applied Science, University of Pennsylvania, Philadelphia, $\mathrm{Pa}$.

Supported by grant HL36308 from the National Heart, Lung, and Blood Institute, National Institutes of Health, Bethesda Md.

Received for publication Feb. 9, 1996; revisions requested March 18, 1996; revisions received April 9, 1996; accepted for publication April 11, 1996.

Address for reprints: L. Henry Edmunds Jr., MD, Department of Surgery, Four Silverstein, Hospital of the University of Pennsylvania, 3400 Spruce St., Philadelphia, PA 19104.

Copyright (C) 1996 by Mosby-Year Book, Inc.

$0022-5223 / 96 \$ 5.00+0 \quad \mathbf{1 2 / 1 / 7 4 1 8 3}$ coordinates of each transducer position are calculated from multiple intertransducer distance measurements by means of multidimensional scaling (MDS). The basic concepts of the method have been recently described and validated, ${ }^{1}$ but the original technology required 15 to 20 minutes to obtain all of the intertransducer distance measurements during steady state conditions, did not include a fixed frame of reference, and did not produce comparably oriented two-dimensional views of transducer locations. $^{1}$

This report describes improved technology that includes an internal anatomic reference frame and permits the measurement of 120 intertransducer distances at $200 \mathrm{~Hz}$. New customized software generates three-dimensional coordinates for each transducer and, when applied to the ovine mitral valve, produces two-dimensional "images" in three orthog- 

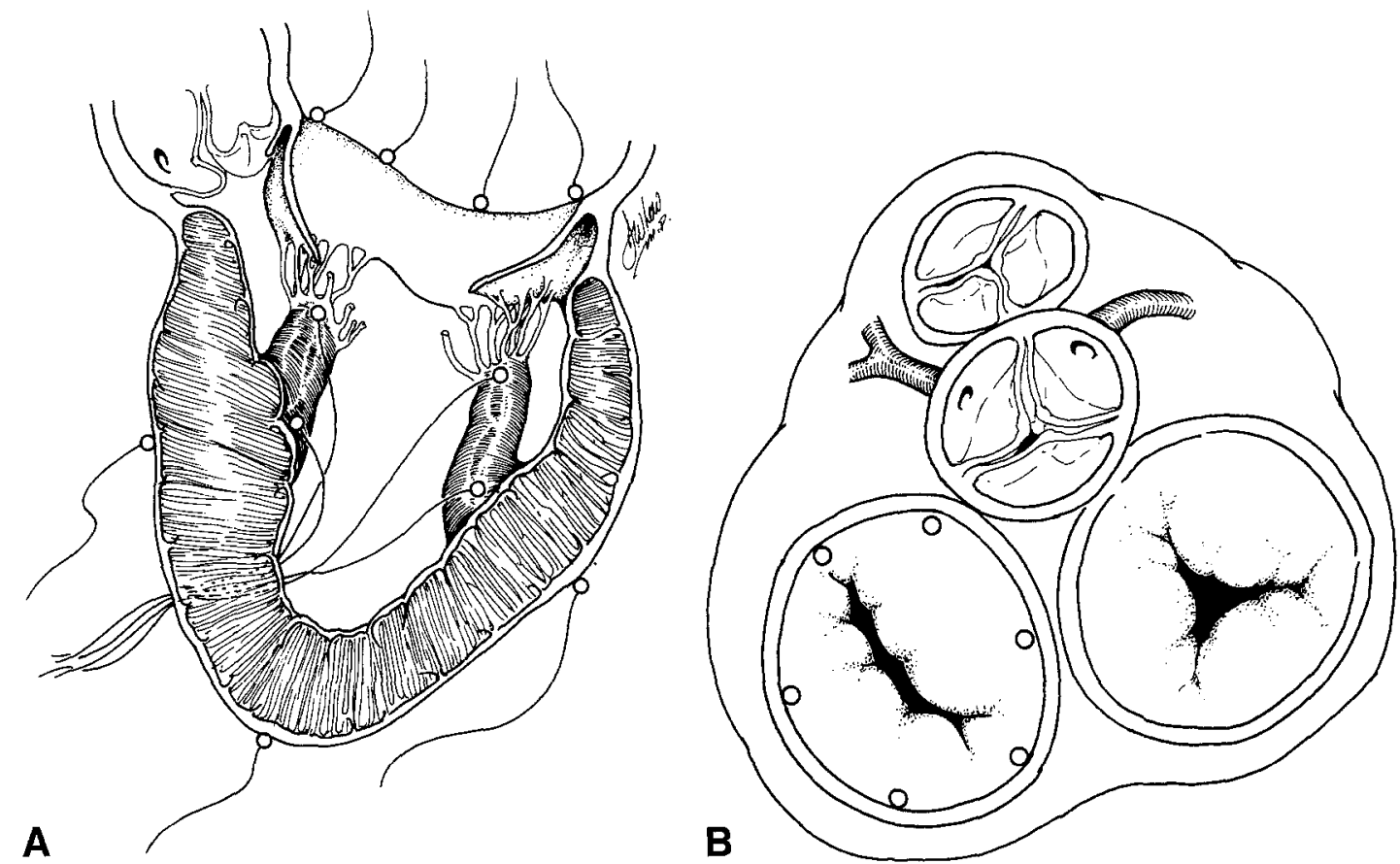

Fig. 1. Positions of the intracardiac, apical, and short axis transducers $(n=13)$. A, Approximate sagittal view; B, atrial view illustrating the approximate positions of six annular transducers. Three additional transducers are attached to the anterior chest wall to form a plane of reference.

onal views throughout the cardiac cycle. The reproducibility of distance measurements and two-dimensional views is assessed and the capability of the method for serial measurements over time is demonstrated. The complex three-dimensional geometric interrelationships of various components of the normal ovine mitral valve during the cardiac cycle is described with unexpected findings.

\section{Methods}

Hardware. The Sonometrics Series 5001 digital sonomicrometer (Sonometrics Corp., London, Ontario, Canada) measures distances in an aqueous medium by means of piezoelectric transducers, a high-frequency counter, and the time-of-flight principle. It is capable of measuring all 120 distances $(\mathrm{n}[\mathrm{n}-1] / 2)$ between 16 transducers once every $5 \mathrm{msec}$. The sonomicrometer consists of four components: (1) a 486-class personal computer that controls sonomicrometry functions and runs applications software; (2) a customized timing board that controls the length of the energizing pulse and the sequence of transducer transmissions; (3) a customized distance-measuring circuit that translates the ultrasonic signal into a distance measurement; and (4) an eightchannel analog-to-digital board that is synchronized with the sonomicrometer distance measurements. The transducers are $3 \mathrm{~mm}$ hemispheric PZT-5A piezoelectric crys- tals (Crystal Biotech, Hopkinton, Mass.). When interfaced with the Sonometrics sonomicrometer, these transducers emit ultrasound at a frequency of $800 \mathrm{kHz}$.

Animal studies. So that the ovine mitral valve can be imaged, 16 transducers are placed as follows. Six transducers are sutured around the mitral valve anulus: one each at the anterior and posterior commissures, two along the anterior leaflet (dividing it into three approximately equal segments), and two along the posterior leaflet. Transducers are also sutured to the tips and bases of both papillary muscles. The short axis of the heart is defined by anterior and posterior epicardial transducers. A third epicardial transducer is placed at the ventricular apex. The final three transducers are sutured to the anterior chest wall and sternum, 3 to $5 \mathrm{~cm}$ apart, to form a triangular anatomic reference frame. Fig. 1 depicts the locations of the 13 cardiac transducers.

In compliance with guidelines for humane care (NIH Publication No. 85-23, revised 1985), anesthesia was induced with sodium thiopental (10 to $15 \mathrm{mg} / \mathrm{kg}$ intravenously in eight Dorsett hybrid sheep (33 to $42 \mathrm{~kg}$ ). They were intubated and anesthetized and ventilated with isoflurane (1.5\% to $2 \%$ ) and oxygen (Dräger anesthesia ventilator, North American Dräger, Telford, Pa.). The sheep received glycopyrrolate $(0.4 \mathrm{mg}$ intravenously) and one dose of cefazolin ( $1 \mathrm{gm}$ intravenously) before the operation and one dose afterward. The surface electrocardiogram and arterial blood pressure were monitored. 
Through a sterile left lateral thoracotomy, the three chest wall transducers were sutured to the sternum and chest wall away from the lung. Three epicardial transducers were sutured to the short axis and apex of the ventricle. After heparin (120 mg intravenously), normothermic cardiopulmonary bypass was started and the heart was electrically fibrillated. The perfusion circuit consisted of a $28 \mathrm{~F}$ wire-wrapped venous cannula (Medtronic Inc., Minneapolis, Minn.) placed into the right ventricle through the main pulmonary artery, a $14 \mathrm{~F}$ wire-wrapped arterial cannula in the left carotid artery, a centrifugal pump with precalibrated electromagnetic flowmeter (Medtronic Inc.), and a bubble oxygenator/heat exchanger (model H-1700, Bard Cardiopulmonary Division, Tewksbury, Mass.). The large left atrial appendage was opened to expose the mitral valve. Under direct vision, 10 endocardial transducers were sutured to the mitral valve as described earlier (see Fig. 1). Polydioxanone hemoclips (Ethicon, Inc., Somerville, N.J.) were placed across the wire at tissue exit points to hold transducers in place. Wires to the papillary muscles were brought out through the left ventricular free wall below the plane of the valve. The annular transducer wires were brought out through the atriotomy. No wire crossed the plane of the mitral valve. After the atrium was closed, the animal was defibrillated and weaned from cardiopulmonary bypass. The 16 color-coded transducer wires were brought out through the chest wall and secured externally by a plastic patch sutured to the skin.

Animals were studied between 10 and 151 days after the instrumentation operation. A total of 17 studies were performed on eight sheep at various intervals. For SAL studies sheep were sedated with thiopental, intubated, and anesthetized with isoflurane. Animals were supine, their lungs mechanically ventilated, and their hearts atrially paced at 120 beats/min. Under sterile conditions a highfidelity pressure transducer (SPC-350, Millar Instruments, Inc., Houston, Tex.) was passed through a cutdown into the left ventricle via the left carotid artery. Surface electrocardiogram and left ventricular pressure were monitored continuously (Hewlett-Packard 78534C monitor, Hewlett-Packard Company, Andover, Mass.). A SwanGanz catheter $(131 \mathrm{H}-7 \mathrm{~F}$, Baxter Healthcare Corp., Irvine, Calif.) was introduced via the right internal jugular vein to measure pulmonary artery and capillary wedge pressures. Thermodilution cardiac output was measured in duplicate before sonomicrometry data were collected. Ventilation was suspended during measurements.

Sonomicrometer settings. Two sonomicrometer settings, pulse length and inhibit delay, are adjusted to maximize the number of measured chord lengths. The pulse length is the time during which a voltage is applied to a transducer to produce sound waves. The applied voltage also produces an electromagnetic pulse that prematurely activates receiving transducers; this artifact necessitates an inhibit delay. A longer pulse length improves signal quality but requires a longer inhibit delay, which increases the minimum distance that can be measured. Adjustments attempt to maximize pulse length and minimize inhibit delay. Data are collected in 5-second runs.

Sonomicrometry signal processing. Spikes caused by noise and intermittent level shifts caused by failure to track the leading wave front of the ultrasound signal are removed at a later time with software produced by Sonometrics Corporation. With the use of customized software (J. T. Streicher) any heartbeat during the data run can be chosen for analysis. Each chord length is examined within the chosen heartbeat. Some chord lengths are not successfully measured and other chord lengths are measured twice. Only one measurement of each chord length is selected for input into the MDS algorithm.

MDS is an iterative technique that calculates threedimensional coordinates from a group of chord lengths. ${ }^{2,3}$ MDS compensates for measurement error in in vivo studies. ${ }^{1}$ MDS also accurately determines any intertransducer distances that are not directly measured (i.e., between two transducers) by establishing the coordinates of the two transducers and calculating the distance between them. Customized software was developed to implement the MDS algorithm (K. B. Gupta). The three-dimensional coordinates for all transducers at all time points in the cardiac cycle are determined.

Within the chosen heartbeat four time points of special interest in the cardiac cycle are identified by means of the electrocardiogram and pressures. (The aortic root pressure trace is first smoothed by applying a high-frequency filter once.) End-diastole is defined as the peak of the QRS complex; end-systole is defined as the maximum negative left ventricular $\mathrm{dP} / \mathrm{dt}^{4}{ }^{4}$ End isovolumic contraction is defined as the first time point at which the aortic root $\mathrm{dP} / \mathrm{dt}$ is greater than zero. End isovolumic relaxation is defined as the time at which the left ventricular pressure is $10 \%$ of $\mathrm{LVP}_{\text {max }}$ and the left ventricular $\mathrm{dP} / \mathrm{dt}$ is less than $0 .^{5}$

Imaging. The three chest wall transducers are used to determine a fixed reference frame and coordinate system in which the 13 transducers attached to the heart are located. Within this fixed reference frame three orthogonal viewing planes are established. These are related to the heart as follows: The first plane is determined by fitting a least-squares plane through the six annular transducers at end-diastole (Fig. 2, annular plane). The second plane is oriented orthogonal to the annular plane and passes through both the centroid of the mitral anulus and the transducer located at the anterior commissure (Fig. 2, sagittal plane). The third plane is oriented orthogonal to the other two planes and also passes through the centroid (Fig. 2, coronal plane). Once these planes are established at end-diastole, they do not change during the cardiac cycle. Individual transducers may move in and out of each viewing plane, but the planes remain fixed.

We generate two-dimensional views of transducer movements by projecting transducer locations in three dimensions onto one of the three orthogonal planes. The projection onto the annular plane is termed the axial view. The area of the anulus is the area of the hexagon of annular transducers in this plane. The projection onto the plane that includes the centroid of the anulus and the anterior commissure is termed the sagittal view. The projection onto the third plane is the coronal view. A best-fit "surface" between the six annular transducers is generated to produce an animated three-dimensional representation of the anulus during the cardiac cycle. 


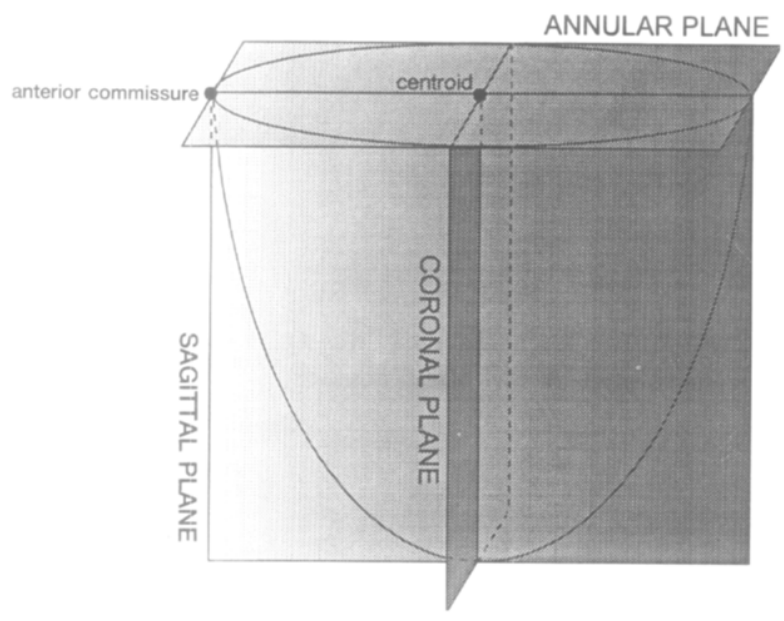

Fig. 2. Three orthogonal imaging planes and their relation to the heart. The annular plane is defined as the least-squares fit through the six annular transducers; because the anulus is saddle-shaped this plane does not necessarily contain either the centroid of the anulus or the anterior commissure.

Ventricular torsion is calculated by means of the definitions depicted in Fig. 3. The midpoint of the line segment joining the anterior and posterior epicardial transducers is determined, and a longitudinal axis from that point to the apical transducer is defined. The orientation of a ventricular or annular transducer with respect to this axis is found by defining a unit vector along a line through the transducer perpendicular to the axis. The intersection of this line with the longitudinal axis provides the axial position ( $l$ ) of the transducer. Arbitrarily, the vector to the posterior commissural transducer is assigned an orientation angle of zero and an axial length of zero $(l=0)$. The axial position of all transducers is defined at end-diastole. The change in orientation vector at any time point indicates rotation and is obtained by subtracting the vector angle at end-diastole from the angle at the time point of interest. Rotations that are in a counterclockwise direction as viewed from the base of the heart toward the apex are defined as positive; clockwise rotations are negative.

As the heart moves during the cardiac cycle the torsion axis moves with it. Axial positions on the torsion axis of individual transducers also change. The torsion between any two individual transducers is found by taking the difference between their respective angular changes and dividing by the difference between their end-diastolic axial positions.

Estimation of reproducibility of intertransducer distance measurements and transducer coordinates. The protocol for determining the reproducibility of SAL distance measurements and transducer coordinates appears in Appendix 1. The effect of variations in sonomicrometry settings and the effects of within-analyst and between-

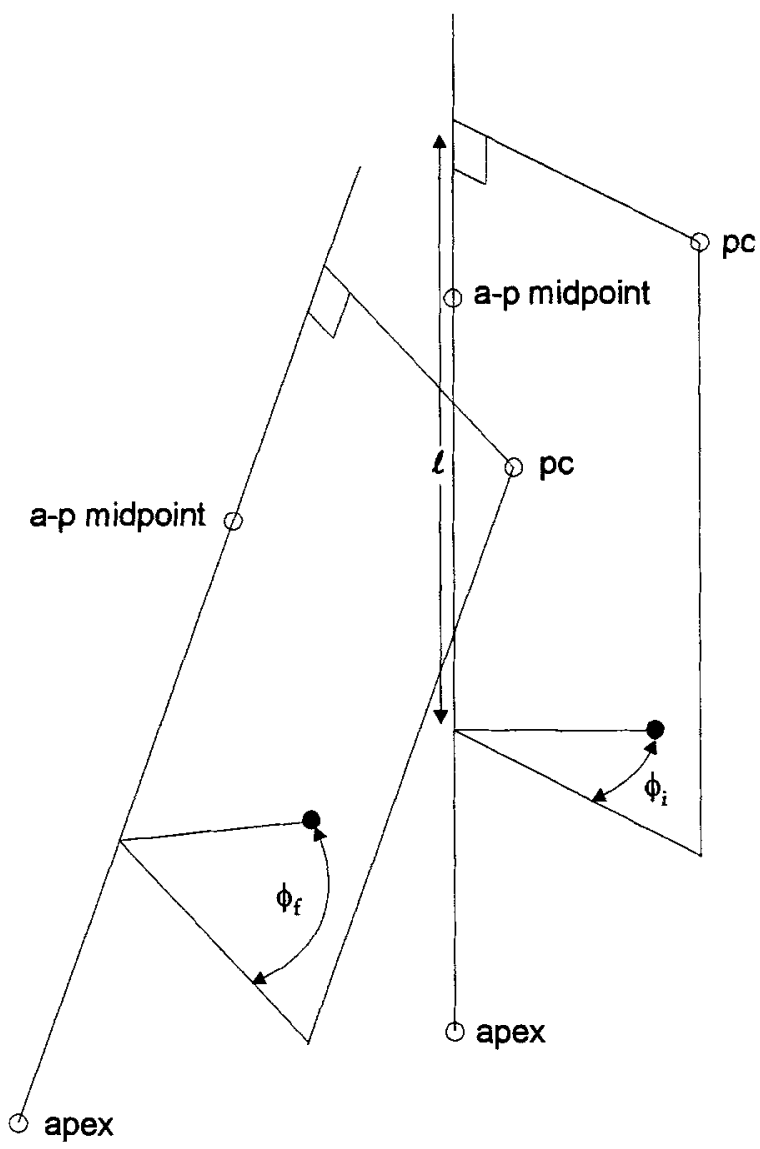

Fig. 3. Definitions used to calculate torsion. The midpoint of the line segment joining the anterior and posterior epicardial transducers is labeled $a-p$ midpoint. The axis of the left ventricle is defined as the line passing through that point and the apical transducer. Average torsion between the base of the heart and the level of any transducer on the endocardium (solid circle) is given by $\left(\phi_{f}-\phi_{i}\right) / l$, where $\phi_{f}$ is a function of time, and $\phi_{i}$ and $l$ are defined at end-diastole. Torsion is measured in degrees per millimeter; positive numbers indicate counterclockwise rotation as viewed along the axis from the base of the heart. $p c$, Posterior commissure transducer.

analyst variability on reproducibility were studied, as was the reproducibility of sequential measurements in the same sheep.

Longevity of sonomicrometry signals. The longevity of a full array $(n=16)$ of sonomicrometry transducer signals was assessed in five sheep, which were monitored until loss of one or more signals or the animal's death.

Anatomy and histology. The attachment of the mitral leaflets to the heart was examined by cutting tissue blocks perpendicular to the plane of the mitral anulus through the valve leaflet, atrium, anulus, and ventricle at multiple 

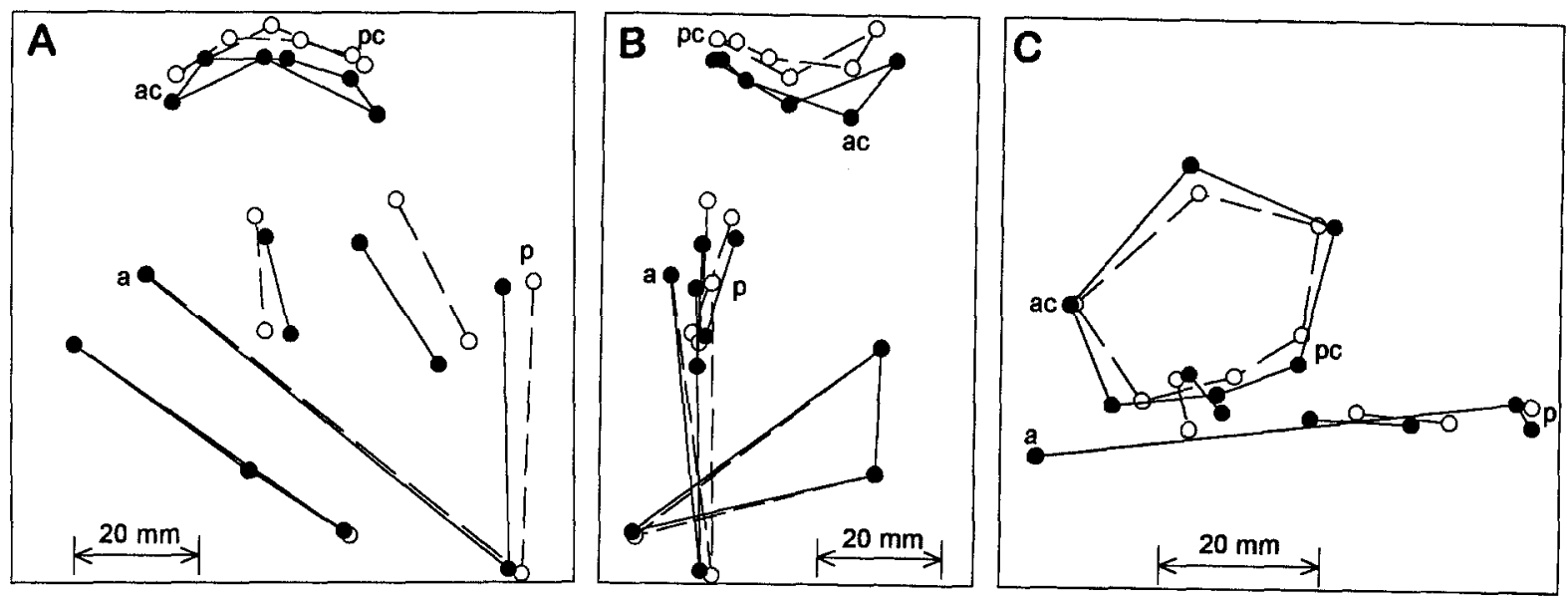

Fig. 4. Three two-dimensional orthogonal views depicting the locations of each transducer at end-diastole and end-systole. A, Sagittal view; B, coronal view; C, axial view. The reference transducers have been omitted from the axial view for clarity. Open circles indicate end-diastole; closed circles, end-systole. $a$, Anterior epicardial short-axis transducer; $p$, posterior short-axis transducer; $a c$, anterior commissure transducer; $p c$, posterior commissure transducer. Solid (end-systole) and dashed lines (end-diastole) are drawn between the six annular transducers in sequence, between the tips and bases of both papillary muscles, between the apical transducer and each epicardial short-axis transducer, and between the three chest wall reference transducers, which do not move appreciably. The heart was atrially paced at 120 beats/min during an infusion of esmolol at $1 \mathrm{mg} / \mathrm{min}$. Cardiac output, $4.0 \mathrm{~L} / \mathrm{min}$; left ventricular pressure, $111 / 6 \mathrm{~mm} \mathrm{Hg}$; aortic pressure, $117 / 85 \mathrm{~mm} \mathrm{Hg}$; pulmonary arterial pressure, $40 / 22 \mathrm{~mm} \mathrm{Hg}$; central venous pressure, $10 \mathrm{~mm} \mathrm{Hg}$. Note that the anulus descends toward the ventricular apex during systole in the sagittal and coronal views and that the apex remains relatively fixed. Also note that the circumference of the ovine mitral anulus is smaller at end-diastole than at end-systole in the axial view.

locations around the anulus in a dog, baboon, two sheep, and a human cadaver. Photographs were taken of the cross sections. In addition, for the sheep, tissue blocks were fixed in formaldehyde, stained in hematoxylin and eosin, and microscopically sectioned perpendicular to the leaflet attachment to the heart.

The total area of the mitral leaflets was determined by planimetry in fresh hearts after euthanasia in three animals in which axial views were obtained during life by SAL. The ratio of leaflet area to maximal annular area was calculated for these sheep.

\section{Results}

Distance measurements. SAL produces distance measurements between any two transducers every $5 \mathrm{msec}$ throughout the cardiac cycle. For the array of 16 transducers approximately 100 sets (depending on heart rate) of 120 distances between transducers are generated. These distance measurements calculated by MDS agree closely with direct measurements between each transducer pair. ${ }^{1}$
Orthogonal two-dimensional views of the mitral valve. Three orthogonal views indicating the locations of all 16 transducers at end-diastole and endsystole are presented in Fig. 4. The images presented in this figure are from a single sheep but are representative of all eight. Although SAL measures chord lengths rather than arc lengths, the method estimates the circumference and area of the mitral anulus. Fig. 4 shows that the area of the mitral orifice in the axial view (Fig. 4, C) is smaller at end-diastole than at end-systole. The descent of the mitral anulus toward the ventricular apex during systole, the nearly constant position of the ventricular apex, and the "saddle-shaped" configuration ${ }^{6}$ of the mitral anulus with depressed commissures are also apparent in these views.

Reproducibility analysis. The results of the reproducibility studies are presented in Table I and show that average variability within and between analysts and resulting from sonomicrometry settings is less than $1 \mathrm{~mm}$ and less than $2 \%$ of the distance 
Table I. Error estimates of sonomicrometry array localization

\begin{tabular}{|c|c|c|c|}
\hline \multirow[b]{2}{*}{ Variable } & \multicolumn{2}{|c|}{ Chord lengths } & \multirow{2}{*}{$\begin{array}{c}\text { Coordinates } \\
\begin{array}{c}\text { Procrustes analysis } \\
(\mathrm{mm})(n=70)\end{array}\end{array}$} \\
\hline & $\begin{array}{c}\text { Mean SD of chord } \\
\text { lengths }(\mathrm{mm})(n=120)\end{array}$ & $\begin{array}{l}\text { Mean normalized \% } \\
\text { error } \pm S D(n=120)\end{array}$ & \\
\hline \multicolumn{4}{|l|}{ Sonomicrometer setting } \\
\hline Analyst 1 (range) & 0.8 & $1.8 \pm 1.5(0.3$ to 9.8$)$ & 2.3 \\
\hline Analyst 2 (range) & 0.7 & $1.7 \pm 1.2(0.4$ to 8.4$)$ & 2.0 \\
\hline \multicolumn{4}{|l|}{ Error estimate within analysts } \\
\hline \multicolumn{4}{|l|}{ Sheep 1} \\
\hline Analyst 1 (range) & 0.8 & $1.2 \pm 1.1(0.1$ to 9.8$)$ & 1.6 \\
\hline Analyst 2 (range) & 0.4 & $0.9 \pm 0.6(0.3$ to 4.4$)$ & 0.9 \\
\hline \multicolumn{4}{|l|}{ Sheep 2: } \\
\hline Analyst 1 (range) & 0.5 & $1.0 \pm 1.2(0.0$ to 7.3$)$ & 0.8 \\
\hline Analyst 2 (range) & 0.3 & $0.8 \pm 0.9(0.1$ to 7.1$)$ & 1.0 \\
\hline Error estimate between analysts (range) & 0.7 & $1.6 \pm 0.3(0.1$ to 9.8$)$ & $2.2^{*}$ \\
\hline Combined variability (range) & 1.0 & $2.4 \pm 0.7(1.3$ to 3.8$)$ & NP \\
\hline
\end{tabular}

$S D$, Standard deviation; $N P$, not performed.

${ }^{*} n=5$.

measured. The combination of all sources of variability averaged only $1.0 \mathrm{~mm}$ or $2.4 \%$ of the distances measured. Reproducibility errors on twodimensional images were similarly small. The average reproducibility in chord lengths of data sets taken on two different days with the same sonomicrometer settings and the same analyst is $1.9 \mathrm{~mm}$ or $4.6 \%$ of the measured distances. The average absolute error in the Procrustes coordinate comparison is $5.2 \mathrm{~mm}$.

Fig. 5 illustrates the precision of SAL for serially tracking tagged cardiac structures. Fig. 5, $A$ plots changes in the area of the mitral anulus derived from two separate SAL measurements taken in a single sheep on consecutive days. Hemodynamic measurements are similar for each data run. Fig. 5, $B$ and $C$ show sagittal views of transducer locations at end-diastole and end-systole on the two separate days. Other views also are nearly identical.

Longevity of sonomicrometry signals. Longevity of transducer arrays implanted in five sheep are shown in Table II. Two sheep died at 60 and 97 days with all transducers functioning; in three sheep all transducers performed satisfactorily for 130 to 151 days.

Anatomy and histology. In sheep, anatomic cross sections show that the leaflets originate from atrial muscle and do not attach to ventricular muscle or the fibrous anulus. (Figs. 6 and 7). This relationship was found in at least three sections obtained from two sheep. In dog, baboon, and human beings, the mitral leaflets are attached to ventricular muscle (Fig. 7). In sheep both papillary muscles are closely associated with the ventricular wall, with only a short length of free unattached muscle (Fig. 8).

In three sheep, the area of the mitral leaflets averaged $1230 \mathrm{~mm}^{2}$ (range 1160 to $1370 \mathrm{~mm}^{2}$ ). The maximum mitral orifice area as estimated by SAL occurs near end isovolumic relaxation and averaged $790 \mathrm{~mm}^{2}$ (range 670 to $950 \mathrm{~mm}^{2}$ ). The mean ratio of leaflet area to orifice area is 1.6 (range 1.4 to 1.8 ).

SAL images of the ovine mitral anulus Fig. 9 is an illustration of the three-dimensional shape of the mitral anulus at end-diastole and end-systole. An arbitrary surface passing through each of the annular transducers has been drawn to better demonstrate the "saddle shape" of the anulus, with apically depressed commisures, which are maintained throughout the cardiac cycle. All sheep studied had anuli of similar shapes.

Fig. 10 is a more comprehensive description of the mitral anulus in one sheep. As viewed in the axial plane there is relatively little change of circumference along the anterior part of the anterior anulus in the area of the fibrous trigone. Most of the change in the annular circumference occurs along the posterior anulus and occurs after end isovolumic contraction in systole and after end isovolumic relaxation in diastole.

Selected intertransducer distances and the annular area, measured for a single heartbeat in one sheep, are shown as a function of time in Fig. 11. The heart was atrially paced at 120 beats $/ \mathrm{min}$. The maximum orifice area occurred near the end of isovolumic relaxation (Fig. 11, $A$ ). The minimum 

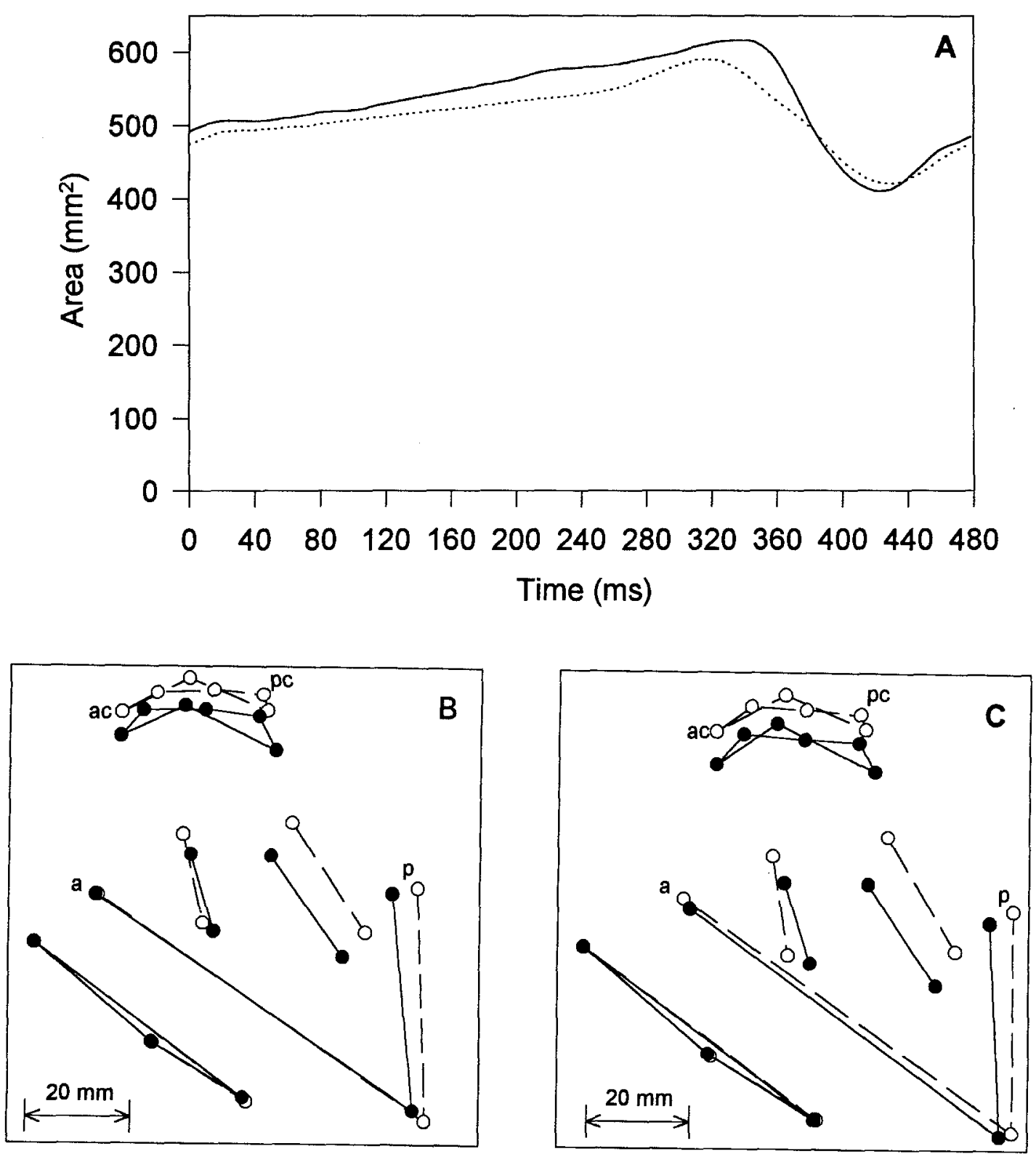

Fig. 5. Changes in mitral valve area (A) and transducer locations in the sagittal view (B and $\mathbf{C}$ ) obtained from a single sheep studied twice 1 day apart. Hemodynamic measurements were obtained during each data run and were nearly identical between days. Sheep were supine, anesthetized, intubated, and not ventilated during data runs. Note that transducer locations are close, but not identical.

orifice area occurred near end-diastole. The two commissures moved apart during isovolumic contraction, and the distance between them did not change during the remainder of systole (Fig. 11,B). The distance between commissures was least immediately before end-diastole.
SAL images of papillary muscles and left ventricle. For both papillary muscles, the maximum change in length during the cardiac cycle is approximately 3 to $3.5 \mathrm{~mm}$ (Fig. 11,C). Ovine papillary muscles are longest during end isovolumic contraction and shortest near the end of relaxation. Note 
Table II. Transducer signal longevity

\begin{tabular}{cc}
\hline Sheep No. & Postop. day of study \\
\hline CR15 & 151 \\
CR18 & 26,97 \\
CR22 & 18,130 \\
CR23 & 14,130 \\
CR27 & $10,16,23,28,29,47,60$ \\
\hline
\end{tabular}

Number indicates postoperative day(s) in which all 16 transducers functioned. In three sheep (CR15, CR22, and CR23) later attempts to record data were made, but one or more transducers failed. The other two sheep became sick and were put to death.

also that at a stroke volume of $33.3 \mathrm{ml}$ the change in the epicardial short axis during the cardiac cycle is only between 5 and $5.5 \mathrm{~mm}$ (Fig. 11, D).

Fig. 12, $A$ shows the rotation of the tips and bases of both papillary muscles around a longitudinal ventricular axis. As viewed from the base of the heart, the base of the posterior papillary muscle rotates counterclockwise and the base and tip of the anterior papillary muscle rotate clockwise. The tip of the posterior papillary muscle undergoes little angular change. This rotational movement of the papillary muscles during the cardiac cycle indicates considerable changes in the direction of the forces tethering the mitral leaflets. Fig. 12, $B$ shows that torsion along the posterior papillary muscle is greater in magnitude and opposite in direction to that along the anterior papillary muscle. During the majority of systole, the posterior papillary muscle is subject to a rapid increase in torsion. During late systole posterior papillary muscle torsion becomes constant for approximately $50 \mathrm{msec}$. With the onset of isovolumic relaxation the posterior papillary muscle sustains a rapid decrease in torsion that continues through the remainder of diastole at a slower rate.

\section{Discussion}

SAL is a new method to accurately determine the three-dimensional locations of tagged cardiac components throughout the cardiac cycle in laboratory animals. The method produces reproducible distance measurements and two-dimensional views of transducer locations for periods ranging from several weeks to a few months. Our previous study ${ }^{1}$ and this one show that signal processing and the MDS algorithm add minimal error to distance measurements between transducers and to three-dimensional transducer coordinates if all transducers continue to function. The addition of a fixed reference frame distinguishes translational movements from

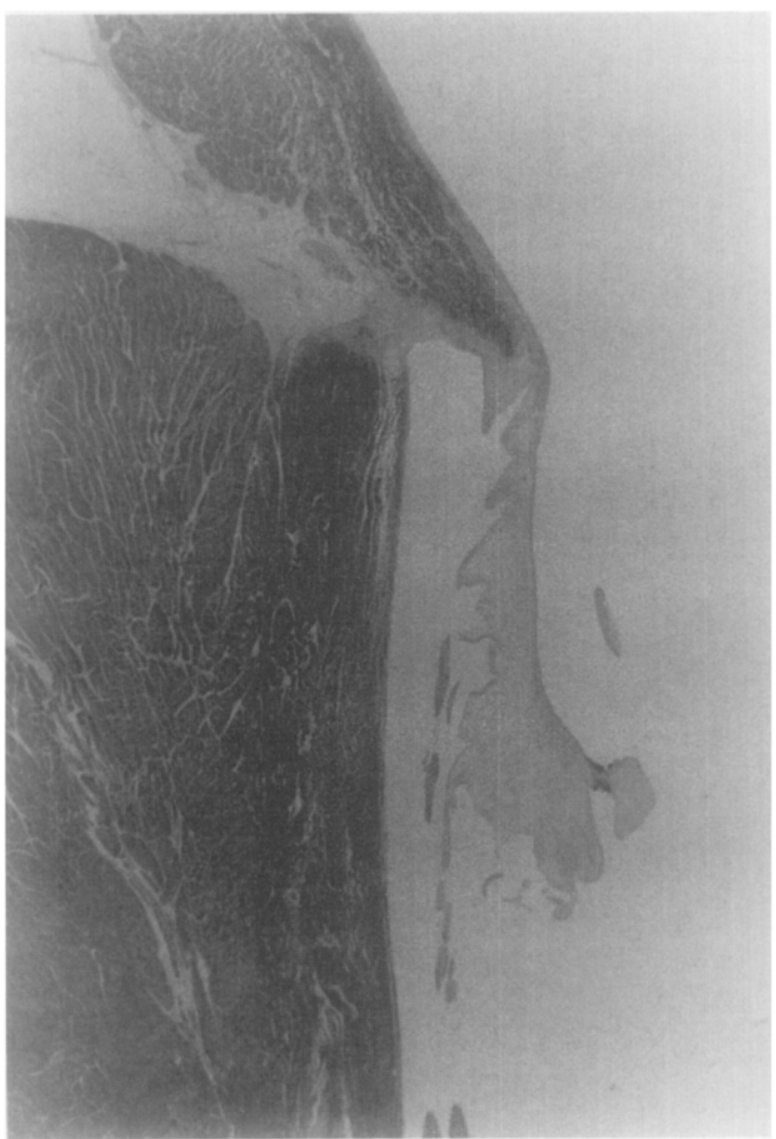

Fig. 6. Histologic section through the hinge point or mitral leaflet-heart junction. Note that left atrial tissue is both above and below the hinge point and that the ovine anulus contains little fibrous tissue. (Original magnification $\times 8$.)

cardiac deformations and allows control of the orientation of imaging planes. Data can now be acquired at $200 \mathrm{~Hz}$. These improvements overcome important limitations of our first-generation studies $^{7,8}$ and greatly expand the utility of the method. SAL can now be used to study cardiac inflow valves and other cardiac structures and to describe remodeling changes that occur over time after experimental myocardial infarction, injury, or disease.

SAL complements other methods of cardiac imaging and has both distinct advantages and limitations. SAL requires surgery to tag specific cardiac structures. Variations in placement of transducers between sheep preclude precise image comparisons between sheep. The ability to track the three-dimensional coordinates of tagged structures in animals serially for several months is an important advan- 

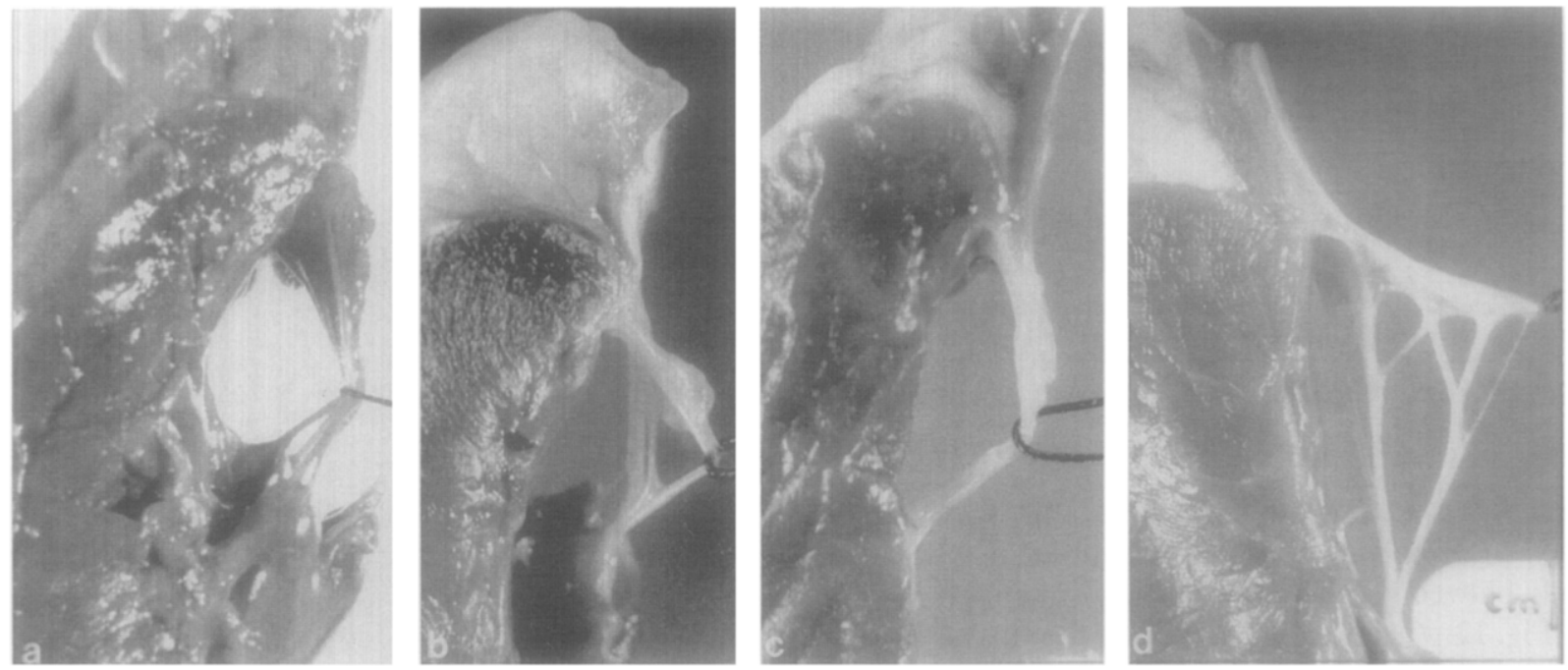

Fig. 7. Mitral leaflet attachment points of four species. A, Human being; B, baboon (Papio anubis); C, mongrel dog; D, hybrid (Dorsett-Blackface) sheep. Mitral valve leaflets attach to ventricular muscle in dog, baboon, and human being but to atrial muscle in sheep.

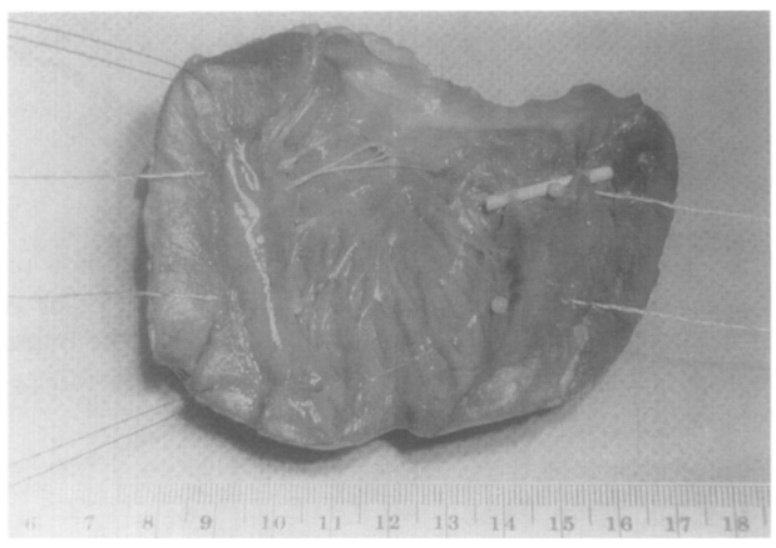

Fig. 8. Integration of the anterior and posterior papillary muscles with the ventricular wall and the relatively short lengths of "free," unattached muscle. Transducers are present at the tips and bases of both papillary muscles.

tage of the method. In contrast, quantitative echocardiography and magnetic resonance imaging depend on anatomic landmarks for location of cardiac structures. ${ }^{9,10}$ Neither method can follow movements of islands of muscle within the heart during remodeling after myocardial infarction. On the other hand, both magnetic resonance imaging and quantitative echocardiography image intracardiac structures with increasing clarity, have good to excellent edge detection, ${ }^{11}$ and can be used clinically.
Each provides additional information, such as Doppler flow measurements or scanning photoacoustic microscopy grid lines ${ }^{12}$ for calculations of regional strains and stresses. ${ }^{13}$

SAL compares most closely with tantalum marker radiography and both complements and competes with that method. Both methods require surgery to place markers in or on anatomic structures within or on the heart, but once placed tantalum markers serve for the life of the animal, whereas sonomicrometry transducers eventually fail. More tantalum markers can be placed than sonomicrometry transducers, and tantalum markers can label more delicate, fast-moving structures because they do not have wires attached. Tantalum markers have been used in human transplanted hearts; current SAL technology cannot provide human data. Both methods have been validated for accuracy ${ }^{14,15}$ and both provide reproducible data with small errors between measurements. Reproducibility of tantalum radiography has been assessed in vitro only. ${ }^{14}$ Data presented in this article demonstrate in vivo reproducibility of SAL. The major limitations of tantalum marker radiography are high capital, engineering, and computer programming requirements; these requirements severely restrict its application. The relative simplicity and low costs of SAL allow other investigators to use this tracking technology in animal models.

Surgical placement of markers, whether sonomi- 

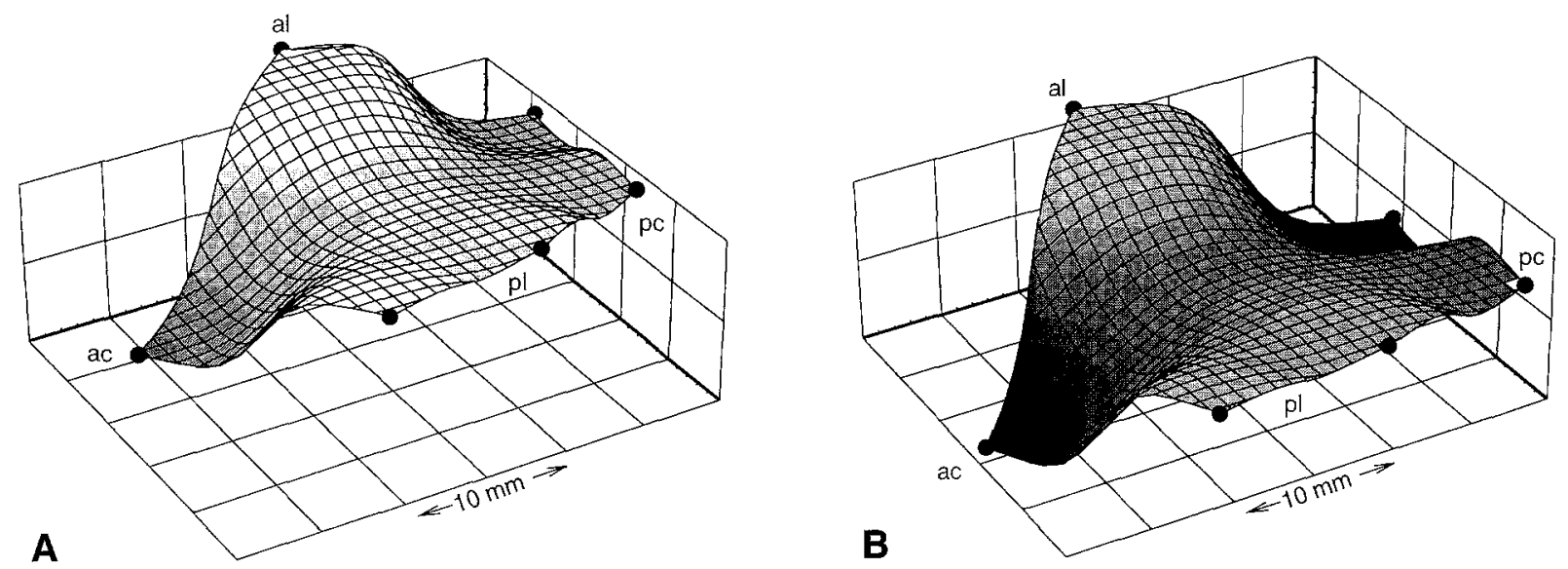

Fig. 9. Three-dimensional depiction of the shape of the mitral anulus at end-diastole and end-systole. Commissures are labeled $a c$ (anterior) and $p c$ (posterior); $a l$ indicates the location of the anterior leaflet hinge point and $p l$ indicates the location of the posterior attachment. The six annular transducers are indicated by solid circles. A surface has been added to emphasize the three-dimensional relationships of the transducer positions around the anulus and the relatively caudad position of the two commissures. A, End-diastole; $\mathbf{B}$, end-systole.

crometry transducers or tantalum markers, reliably identifies the labeled anatomic structures and permits precise (see reproducibility studies herein) measurements between markers within that heart. Because different animals are not precisely identical and because no surgeon can place each marker in the same three-dimensional anatomic position in different hearts, both methods provide primarily qualitative comparisons between hearts and animals. Distances between markers are measured with great precision by both methods, ${ }^{1,14,15}$ but the anatomic variations between hearts and differences in surgical placement significantly increase the standard deviation of measurements even if data are normalized for animal size. Nevertheless, the precision of serial comparisons within hearts over time provide important and otherwise unattainable quantitative information regarding ventricular deformations during the cardiac cycle and over days, weeks, and months (and years with tantalum).

Ventricular deformations during the cardiac cycle are complex and difficult to describe in quantitative terms. Together, the arrangement of ventricular muscle bundles and the time-dependent dynamics of the left ventricle preclude simplistic models of dynamic geometric changes in both healthy and diseased hearts. Ventricular torsion is particularly difficult to quantify by existing clinical imaging methods. Reliable data have been obtained with tantalum radiography. ${ }^{16-18} \mathrm{SAL}$ provides a relatively simple method for studying ventricular torsion and

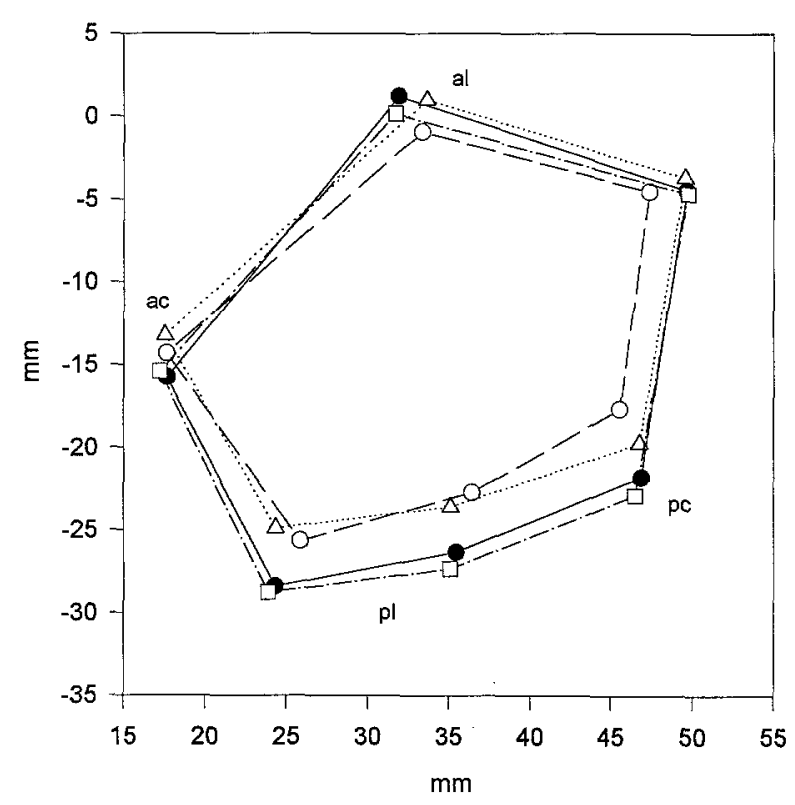

Fig. 10. Axial view at four time points in the cardiac cycle of the six annular transducers. Transducers at end-diastole are represented by open circles, at end isovolumic contraction by open triangles, at end-systole by solid circles, and at end isovolumic relaxation by open squares. See Fig. 4 for abbreviations and hemodynamics. Note that there is minimal change in the anulus during isovolumic relaxation and minimal change in the anterior circumference of the anulus (at the top in the figure) at all time points. The greatest change in the sheep anulus occurs with atrial contraction during late diastole because the ovine mitral leaflets attach to the left atrium. There is minimal rotation of annular transducers around the centroid of the anulus during the cardiac cycle. 


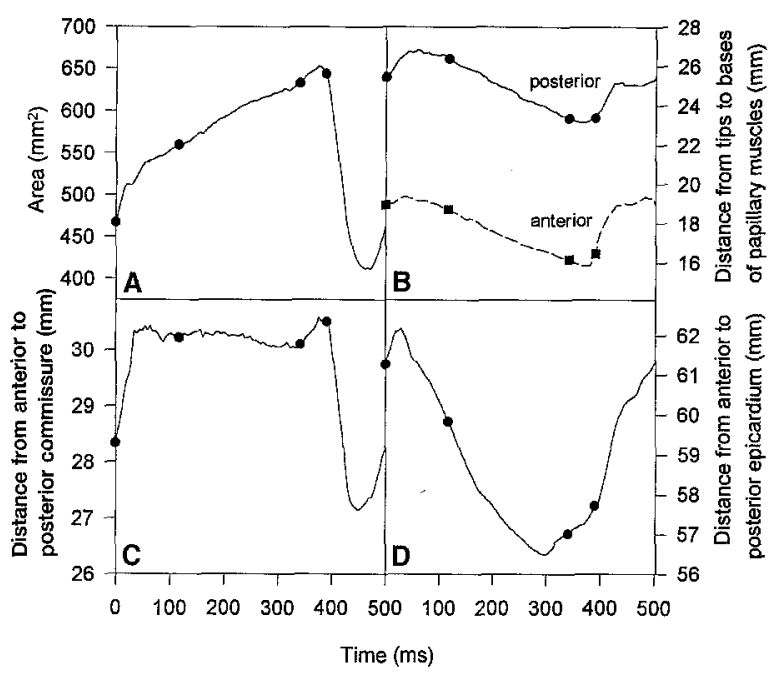

Fig. 11. Changes in the relationships of various mitral valve components during the cardiac cycle. The sheep heart was atrially paced at $120 \mathrm{beats} / \mathrm{min}$. A, Changes in annular area as calculated in the axial view. B, Changes in the transannular distance between commissures. C, Changes in the distance measurements between papillary muscle tips and bases. In sheep the bases of both papillary muscles are not discrete; therefore placement of basal transducers and papillary muscle lengths vary between sheep. Note that the maximal shortening of each papillary muscle is only about 3 to $3.5 \mathrm{~mm}$ or approximately $9 \%$ to $13 \%$. D, Changes in the epicardial short axis.

is particularly applicable to studies of the mitral valve. Varying placement of transducers allows endocardial, midwall, and epicardial ventricular torsion to be separately studied. With SAL, torsion can be measured relative to a ventricular longitudinal axis or relative to other axes that may have more relevance to a particular function or pathologic state.

The sheep is an almost ideal model of ischemic heart disease. Unlike other large animal models, ${ }^{19-22}$ the sheep does not have preformed coronary arterial collateral vessels and has highly reproducible coronary anatomy. ${ }^{23,24}$ Anteroapical left ventricular aneurysm, ${ }^{23}$ postinfarction ventricular arrhythmias, ${ }^{25,26}$ and acute and chronic ischemic mitral regurgitation ${ }^{7,8,24,27}$ are reliably produced by occlusion of selected coronary arteries. These diseases occur in patients who have more varied coronary arterial anatomy ${ }^{28}$ but in patients correlation between coronary anatomy and development of ischemic mitral insufficiency or arrhythmias is much less predictable $^{29,30}$ than in sheep. The availability, cost,
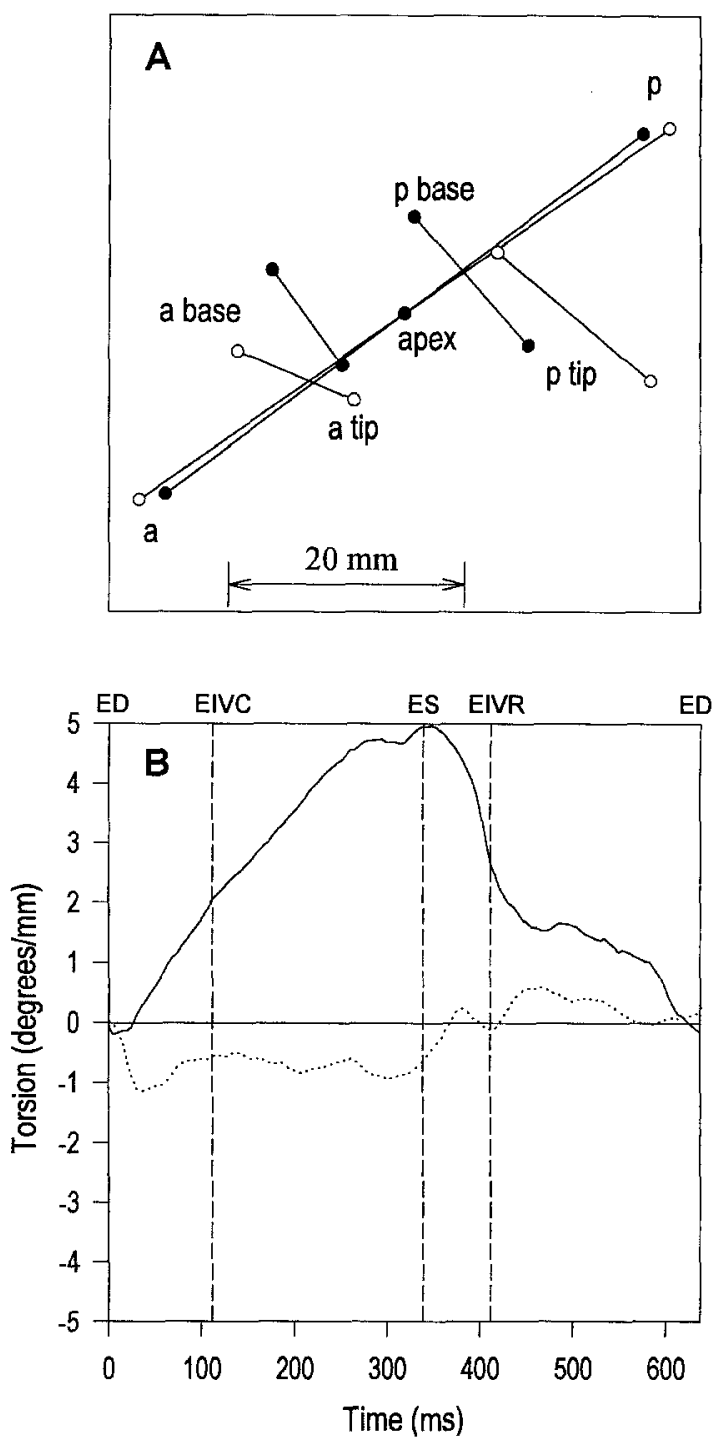

Fig. 12. A, Plot of the rotational movement of both papillary muscle bases and tips around a left ventricular long axis between the apex and midpoint of the epicardial short axis ( $a$ and $p$ ) at end-diastole (open circles) and end-systole (closed circles). The view is from base toward apex; scale shown applies to both directions. The base of the posterior papillary muscle ( $p$ base) rotates counterclockwise during systole, but the base of the anterior papillary muscle (a base) rotates clockwise. The tip of the anterior papillary muscle (a tip) also rotates clockwise. B, Average torsion of each papillary muscle as a function of time. As viewed from the base, counterclockwise torsion is positive and clockwise torsion is negative. Note that the anterior papillary muscle (dotted line) undergoes relatively little torsion compared with the posterior papillary muscle (solid line). Seven sheep studied demonstrated similar torsion of the papillary muscles; only one is shown here. $E D$, End-diastole; $E I V C$, end isovolumic contraction; $E S$, end-systole; EIVR, end isovolumic relaxation. 
size, and docility of sheep are other important advantages.

The ovine mitral valve functions similarly to that of the human being, baboon, and dog but differs in anatomic details. In sheep the mitral leaflets attach to atrial muscle rather than to ventricular muscle. The valve also differs with respect to the length of free papillary muscle. The fact that these anatomic differences do not impair function raises the question of their importance in exercise and pathologic states, such as ischemic mitral regurgitation. The area of ovine mitral leaflets is approximately 1.6 times the area of the mitral orifice during isovolumic relaxation, when the valve is closed. This ratio has been estimated in cadavers ${ }^{31}$ but not with in vivo measurements of mitral orifice area. The amount of actual papillary muscle shortening is approximately 2 to $3 \mathrm{~mm}$ in sheep ${ }^{8}$ and dog. ${ }^{5}$ However, the impact of this shortening on the closing geometry of the mitral valve may be relatively small compared with the descent of the mitral anulus toward the ventricular apex, rotational movement of the posterior papillary muscle around the longitudinal axis of the left ventricle, and concentric narrowing of the ventricle along the short axes. These spatial deformations of the normal ovine valve are probably relevant to the mechanisms that produce postinfarction mitral regurgitation. ${ }^{7,8}$

This study illustrates an application of SAL for study of the dynamic, three-dimensional geometry of the normal ovine mitral valve. This work points out some unique anatomic characteristics of the sheep valve and provides new quantitative information regarding left ventricular deformations relative to the mitral valve during the cardiac cycle. This new imaging technology combined with ovine models of ischemic heart disease is particularly promising for study of ventricular remodeling after myocardial infarction.

We thank Nicolas Gikakis, Michelle Money, and Dr. Yugi Hiramatsu for their invaluable help in these studies.

\section{REFERENCES}

1. Ratcliffe MB, Gupta KB, Streicher JT, Savage EB, Bogen DK, Edmunds LH Jr. Use of sonomicrometry and multidimensional scaling to determine the three-dimensional coordinates of multiple cardiac locations: feasibility and initial implementation. IEEE Trans Biomed Eng 1995;42:587-98.

2. Young FW. Multidimensional Scaling, history, theory and applications. Hillsdale (NJ): Erlbaum Press, 1987.

3. Spencer R. Similarity mapping. Byte 1986;11:85-92.

4. Alyono D, Larson VE, Anderson RW. Defining end systole for end-systolic pressure-volume ratio. J Surg Res 1985;39: 344-50.

5. Rayhill SC, Daughters GT, Castro LJ, Niczyporuk MA, Moon MR, Ingels NB Jr, et al. Dynamics of normal and ischemic canine papillary muscles. Circ Res. 1994;74:11791187.

6. Levine RA, Handschumacher MD, Sanfilippo AJ, Hagege AA, Harrigan P, Marshall JE, et al. Three-dimensional echocardiographic reconstruction of the mitral valve, with implications for the diagnosis of mitral valve prolapse. Circulation 1989;80:589-98.

7. Gorman RC, McCaughan JS, Ratcliffe MB, Gupta KB, Streicher JT, Ferrari VA, et al. Pathogenesis of acute ischemic mitral regurgitation in three dimensions. J Thorac Cardiovas Surg. 1995;109:684-693.

8. Gorman RC, McCaughan JS, Ratcliffe MB, Gupta KB, Guy TS, Edmunds LH Jr. A three-dimensional analysis of papillary muscle spatial relationships in acute postinfarction mitral insufficiency. Surg Forum. 1994;45:330-4.

9. St. John Sutton MG, Overshaw PJ, Kottler MN. Text of echocardiography and Doppler in adults and children. Boston: Blackwell Scientific, 1995.

10. Higgins $\mathrm{CB}$. Newer cardiac imaging techniques (computed tomography, magnetic resonance imaging). In: Braunwald $\mathbf{E}$, editor. Heart disease. Philadelphia: WB Saunders, 1992:31241.

11. Handschumacher MD, Lethor J-P, Siu SC, Mele D, Rivera $\mathrm{JM}$, Picard $\mathrm{MH}$, et al. A new integrated system for three dimensional echocardiographic reconstruction: development and validation for ventricular volume with application in human subjects. J Am Coll Cardiol 1993;21:743-53.

12. Axel L, Dougherty L. MR imaging of motion by spatial modulation of magnetization. Radiology 1989;171:841-5.

13. Krammer CM, Lima JAC, Reichek N, Ferrari VA, Llaneras MR, Palmon LC, et al. Regional differences in function within noninfarcted myocardium during left ventricular remodeling. Circulation 1993;88:1279-88.

14. Daughters GT, Sanders WJ, Miller DC, Schwartzkopf A, Mead CW, Ingels NB. A comparison of two analytical systems for 3-D reconstruction from biplane videoradiograms. Proc Comp Cardiol (IEEE) 1988;15:79-82.

15. Niczyporuk MA, Miller DC. Automatic tracking and digitization of multiple radiopague myocardial markers. Comput Biomed Res 1991;24:129-42.

16. Moon MR, Ingels NB Jr, Daughters GHT II, Stinson EB, Hansen DE, Miller DC. Alterations in left ventricular twist mechanics with inotropic stimulation and volume loading in human subjects. Circulation 1994;89:142-50.

17. Hansen DE, Daughters GT, Alderman EL, Ingels NB, Stinson EB, Miller DC. Effect of volume loading, pressure loading, and inotropic stimulation on left ventricular torsion in humans. Circ Res 1988;62:941-52.

18. DeAnda A Jr, Moon MR, Yun KL, Daughters GT II, Ingels NB Jr, Miller DC. The immediate effects of cardiac surgery on left ventricular torsional dynamics. Circulation 1994; 90(Suppl):II339-46.

19. Gallagher KP, Osakada G, Matsuzaki M, Miller M, Kemper WS, Ross J Jr. Nonuniformity of inner and outer systolic wall thickening in conscious dogs. Am J Physiol 1985;249:H241-8.

20. Blair E. Anatomy of the ventricular coronary arteries in the dog. Circ Res 1961;9:333-41.

21. Tsakiris AG, Rastelli GC Amorim DD, Titus JL, Wood EH. 
Effect of experimental papillary muscle damage on mitral valve closure in intact anesthetized dogs. Mayo Clin Proc 1970;45:275-85.

22. Kaul S, Spotnitz WD, Glasheen WP, Touchstone DA. Mechanism of ischemic mitral regurgitation. Circulation 1991;84: 2167-80.

23. Markovitz LJ, Savage EB, Ratcliffe MB, Bavaria JE, Kreiner $\mathrm{G}$, Iozzo RV, et al. A large animal model of left ventricular aneurysm. Ann Thorac Surg 1989;48:838-45.

24. Llaneris M, Nance ML, Streicher JT, Lima JA, Savino JS, Bogen DK, et al. A large animal model of ischemic mitral regurgitation. Ann Thorac Surg 1994;57:432-9.

25. Kreiner G, Gottleib CD, Yeh I-T, Satoshi F, Miller JM, Edmunds LH Jr, et al. Ventricular tachycardia in an ovine model of left ventricular aneurysm. Surg Forum 1989;40:21921.

26. Kreiner G, Gottlieb CD, Furukawa S, Simson MB, Tyson GS, Edmunds LH Jr. Late potentials in an ovine model of acute transmural myocardial infarction. J Appl Physiol 1992;73: 841-6.

27. Llaneris M, Nance ML, Streicher JT, Linden PL, Downing SW, Lima JAC, et al. Pathogenesis of ischemic mitral insufficiency. J Thorac Cardiovasc Surg 1993;105:439-44.

28. James TN. Anatomy of the coronary arteries in health and disease. Circulation 1965;32:1020-33.

29. Frantz E, Weininger F, Oswald H, Fleck E. Predictors for mitral regurgitation in coronary artery disease. In: Vetter HO, Hetzer R, Schmutzler H, editors. Ischemic mitral incompetence. New York: Springer-Verlag, 1991:57-74.

30. Becker AE. Anatomy of the coronary arteries with respect to chronic ischemic mitral regurgitation. In: Vetter HO, Hetzer $\mathrm{R}$, Schmutzler $\mathrm{H}$, editors. Ischemic mitral incompetence. New York: Springer-Verlag, 1991:17-24.

31. Chiechi MA, Lees WM, Thompson R. Functional anatomy of the normal mitral valve. J Thorac Surg 1956;32:378-98.

32. Mardia KV, Kent JT, Bibby JM. Multivariate analysis. London: Academic Press, 1980:416-9.

33. Gower JC. Statistical methods of comparing different multivariate analyses of the same data. In: Hodson FR, Kendall DG, Tautu P, editors. Mathematics in the archaeological and historical sciences. Edinburgh: University Press, 1971:138-49.

34. Green BF. The orthogonal approximation of an oblique structure in factor analysis. Psychometrica 1952;17:429-40.

\section{Appendix 1}

Estimation of reproducibility of intertransducer distance measurements and transducer coordinates. Differences in sonomicrometry settings, selection of data for analysis, and processing may affect reproducibility of sequential distance measurements and coordinate locations. Therefore variations in sonomicrometry settings and the effects of within-analyst and between-analyst variability on reproducibility and the reproducibility of sequential measurements in the same sheep were studied.

Reproducibility between sonomicrometer settings. Within 2 minutes in a monitored, anesthetized, hemodynamically stable sheep five data sets, each lasting 5 seconds and each at a different sonomicrometer setting, were recorded. A single heartbeat was selected from each data set; a total of five heartbeats were processed. For each selected heartbeat, all intertransducer chord lengths were determined at end-diastole by means of MDS. The five measurements of each of the 120 end-diastolic chord lengths were averaged $(n=5)$ and a standard deviation for each of the 120 chord lengths was calculated. The normalized error for each individual chord length was estimated by dividing the standard deviation by the mean of the five measured chord lengths for each of the 120 distances. This normalized error for each of the 120 distances was averaged and tabulated as a mean, standard deviation, and range.

The five data sets were also compared by means of the least-squares Procrustes rotation algorithm. ${ }^{32-34}$ This technique compares three-dimensional coordinates from two separate data sets by superimposing the two data sets. The second data set $\mathbf{Y}$ is rotated and translated with respect to the first data set $\mathbf{X}$ so that the residual sum of the squares is minimized. The residual sum of the squares is defined:

$$
\mathrm{R}^{2}=\sum_{\mathrm{r}=1}^{\mathrm{n}}\left|\left(\mathrm{x}_{\mathrm{r}}-\mathrm{A}_{\mathrm{r}}^{\prime} \mathrm{y}_{\mathrm{r}}-\mathrm{b}\right)\right|^{2}
$$

where $x_{r}$ and $y_{r}$ are the individual points of $\mathbf{X}$ and $\mathbf{Y}, \mathbf{A}^{\prime}$ is the rotation matrix, and $\mathbf{b}$ the translation vector that operates on $\mathbf{Y}$. Values of $\mathbf{A}^{\prime}$ and $\mathbf{b}$ are obtained such that $R^{2}$ is minimized.

The average absolute error $E$, which has units of length, is defined:

$$
E=\sum_{r=1}^{n}\left|\left(x_{r}-A_{x}^{\prime} y_{r}-b\right)\right|
$$

The minimum $R^{2}$ and the corresponding $E$ were calculated for each data set comparison. Calculations were performed on an 80486-based personal computer (Gateway 2000 Inc., North Sioux City, S.D.) with source code written in C (M. B. Ratcliffe).

Between any two heartbeats the Procrustes technique determines an average absolute error for the array of 16 transducers. Each of the five heartbeats processed was compared with each of the other four; therefore ten Procrustes comparisons were made. The mean of the ten average absolute errors was calculated. This procedure was followed twice, once by each of two analysts.

This protocol does not differentiate between withinanalyst variability and the variability caused by changes in sonomicrometer settings. However, the variability associated with adjustment of the sonomicrometer can be estimated by the difference between these average normalized errors and the within-analyst normalized errors that were determined as described below.

Reproducibility within analysts. An analyst adjusted the sonomicrometer for pulse length and inhibit delay and recorded five data sets of five seconds each from an anesthetized, stable sheep. The same analyst selected and processed a single heartbeat from each of the five data sets obtained. An average normalized error was calculated as described earlier. The five heartbeats were also compared by means of the Procrustes algorithm. This complete protocol was repeated by a second analyst and again separately by both analysts on a second sheep. 
Reproducibility between analysts. Five data sets, each at a different sonomicrometry setting, were recorded. Each of two analysts processed a single heartbeat (not necessarily the same heartbeat) from each of the five data sets, and all intertransducer distances were determined at end-diastole by means of MDS. This produced five pairs of heartbeats, one from each analyst at each sonomicrometer setting, which were compared as follows. The two measurements of the 120 end-diastolic chord lengths were averaged $(n=2)$ and the absolute difference for each of the 120 chord lengths was determined. The normalized error for each chord length was estimated by dividing the absolute difference by the mean of the two measurements, and the mean of these 120 normalized errors was found. Each pair of heartbeats was also compared by use of the Procrustes algorithm. The mean, standard deviation, and range of five normalized distance errors and the mean of five Procrustes absolute errors were calculated.

Combined reproducibility. An estimate of the effect of total potential variability on the reproducibility of the technique was performed. Five data sets, at a single sonomicrometer setting, were collected. The sonomicrometer settings were changed, and another five data sets were recorded. One heartbeat from each of the first five data sets was reduced by one analyst; the second analyst processed one heartbeat from each of the second five data sets. Each data set processed by analyst 1 was compared with each data set processed by analyst 2 , for a total of 25 comparisons. For each comparison, a mean normalized chord length error was calculated and a Procrustes rotation was performed.

Reproducibility between study sessions. Data were collected from the same sheep during two study sessions 24 hours apart. The hemodynamic conditions on both days were similar. The sonomicrometer settings and analyst were the same for both sessions. The two data sets were compared by calculating the average difference and average percent difference of all 120 chord lengths, as well as applying the Procrustes algorithm to assess the differences in crystal coordinates between data sets.

\section{Appendix 2}

The Procrustes rotation is a least-squares method used to superimpose and compare two multidimensional configurations. Let $\mathbf{X}$ be an $n \times p$ matrix of the coordinates of $n$ points obtained by one measurement method. Let $\mathbf{Y}$ be another $n \times p$ matrix of the coordinates of those same $n$ points obtained by a different measurement method. The residual sum of squares of $\mathbf{Y}$ relative to $\mathbf{X}$ is:

$$
\sum_{r=1}^{n}\left|\left(x_{r}-y_{r}\right)\right|^{2}
$$

where $x_{r}$ and $y_{r}$ are the individual points of $\mathbf{X}$ and $\mathbf{Y}$ respectively. The residual sum of squares can be minimized by rotating or translating $\mathbf{Y}$ relative to $\mathbf{X}$ as follows:

$$
A_{r}^{\prime} y_{r}-b, r=1, \ldots, n
$$

where $\mathbf{A}^{\prime}$ is the transpose of a $\mathrm{p} \times \mathrm{p}$ orthogonal matrix. If equations 1 and 2 are combined in the following equation:

$$
R^{2}=\sum_{r=1}^{n}\left|\left(x_{r}-A_{r}^{\prime} y_{r}-b\right)\right|^{2}
$$

and values of $\mathbf{A}^{\prime}$ and $\mathbf{b}$ are obtained such that $\mathbf{R}^{2}$ is minimized, then $\mathbf{Y}$ is superimposed on $\mathbf{X}$. Values of $\mathbf{A}^{\prime}$ and $\mathbf{b}$ are obtained in the following manner. Let

$$
\mathrm{Z}=\mathrm{Y}^{\prime} \mathrm{X}
$$

where $\mathbf{Y}^{\prime}$ is the transpose of $\mathbf{Y}$. By singular value decomposition:

$$
\mathrm{Z}=\mathrm{V}^{\mathrm{U}} \mathrm{U}^{\prime}
$$

where $\mathbf{V}$ and $\mathbf{U}$ are orthogonal $(\mathrm{p} \times \mathrm{p})$ matrices, $\mathbf{U}^{\prime}$ is the transpose of $\mathbf{U}$, and $\Gamma$ is a diagonal matrix of nonnegative elements. The minimizing solution for equation 3 is given by:

$$
\mathrm{b}=0, \mathrm{~A}=\mathrm{V} \mathrm{U}^{\prime}
$$

and further:

$$
\mathrm{R}^{2}=\operatorname{tr} X \mathrm{X}^{\prime}+\operatorname{tr} Y \mathrm{Y}^{\prime}-2 \operatorname{tr} \Gamma
$$

where $t r$ is the trace of a matrix, $\mathbf{X}^{\prime}$ is the transpose of $\mathbf{X}$, and $\mathbf{Y}^{\prime}$ is the transpose of $\mathbf{Y}$.

\section{Commentary}

Gorman and associates present an elegant study providing information important to the physiology of mitral valve function and of mitral valve repair and replacement. This study, like that of Komeda and associates, ${ }^{1}$ documents the precise spatial relationships of various parts of the mitral valve relative to the left ventricle and to the chest wall throughout the cardiac cycle. Although the study examined anesthetized, normal sheep, their data have several implications for human beings with mitral valve disease:

1. The saddle shape of the normal mitral valve throughout the cardiac cycle is confirmed. The importance of maintaining this shape during mitral valve operations remains highly debated.

2. Systolic torsion of the left ventricle is confirmed, as demonstrated by others using magnetic resonance and tantalum radiography. The effects of mitral valve surgery on left ventricular torsion and the significance of these effects are only now being assessed.

3. Gorman and associates ${ }^{1}$ clearly show that the papillary muscles rotate relative to the mitral valve anulus during the cardiac cycle, and this rotation is greatest for the posterior papillary muscle. This finding suggests that, as viewed from the left atrium, surgically placed artificial chordae or transposed chordae would most optimally be oriented in a counterclockwise direction relative to the anulus to maintain normal left ventricular torsion. While chordal placement during mitral valve repair is more directed by reconstructing normal anatomic relationships, placement of artificial chordae during mitral valve replacement when the native chordae are absent ${ }^{2}$ is entirely 
at the discretion of the surgeon, who would be wise to heed the findings of Gorman, and Komeda, and their colleagues. ${ }^{1}$

4. Gorman and coworkers graphically demonstrate several geometric aspects of normal mitral function that may be of relevance to the pathophysiology and repair of ischemic mitral regurgitation. These include papillary muscle shortening, mitral valve descent toward the apex in systole, rotation of the posterior papillary muscle relative to the anulus, and narrowing of the ventricular cavity. The relative roles of these factors in ischemic mitral regurgitation are yet to be demonstrated.

As Gorman and associates suggest, the technique of sonomicrometry array localization (SAL) has merit as a relatively inexpensive laboratory technique to precisely assess cardiac geometry after mitral valve operation, after myocardial infarction, and in the presence of mitral valve disease. Like any good study, this work demonstrates many areas in which further work is needed to fill gaps in our current knowledge. Future studies using the techniques of Gorman and colleagues may suggest refinements of mitral valve repair and replacement techniques that will improve the applicability of mitral valve repair and improve the functional results of mitral valve operations.

Donald D. Glower

Associate Professor of Surgery Duke University Medical Center

Durham, NC 27710

\section{REFERENCES}

1. Komeda M, Glasson JR, Bolger AF, Levitt D, Daughters GT, Niczyporuk MA, et al. Dynamic geometry of normal mitral annulus and papillary muscles. Circulation 1995;92:I515.

2. David TE. Papillary-muscle-annular continuity: Is it important? J Card Surg 1994;9(Suppl):252-4.

$12 / 1 / 75206$ 